\title{
A randomised controlled trial of preinduction cervical ripening- dinoprostone versus foleys catheter
}

\author{
Mumtaj M. ${ }^{1 *}$, Harilakshmi M. ${ }^{2}$ \\ ${ }^{1}$ Department of Obstetrics and Gynecology, Thanjavur Medical College, Thanjavur, Tamil Nadu, India \\ ${ }^{2}$ Department of Obstetrics and Gynecology, K.A.P. Viswanatham Government Medical College, Tiruchirapalli, Tamil \\ Nadu, India
}

Received: 15 March 2017

Accepted: 21 April 2017

\author{
*Correspondence: \\ Dr. Mumtaj M., \\ E-mail: mumtajanifa@gmail.com
}

Copyright: (c) the author(s), publisher and licensee Medip Academy. This is an open-access article distributed under the terms of the Creative Commons Attribution Non-Commercial License, which permits unrestricted non-commercial use, distribution, and reproduction in any medium, provided the original work is properly cited.

\begin{abstract}
Background: Cervical ripening before induction of labour in women with unfavourable cervix is essential to shorten the induction to delivery interval and avoid unnecessary interventions.

Methods: The study was carried out at Raja Sir Ramasamy Mudaliar hospital, Chennai during the period August 2012 to July 2013. 200 antenatal women were recruited and randomly allocated to Foleys and prostaglandin E2 gel group for induction. The change in bishops score, induction to delivery interval, mode of delivery, vaginal delivery within 24 hours, maternal complications, fetal outcome between both groups were compared.

Results: The commonest indication for induction in both groups was postdated pregnancy followed by oligohydramnios in Foleys group and preeclampsia in PGE2 group. Foleys catheter induction improves bishops score better compared to PGE2 gel whereas PGE2 gel causes a significant reduction in the mean induction to delivery interval between the two groups. However, there was no significant difference between mean caesarean deliveries between the two groups. In both Foleys and the PGE2 group, failed induction was the commonest indication for caesarean section. The number of patients delivering vaginally within $24 \mathrm{hrs}$ was similar between the two groups.

Conclusions: Though prostaglandins are a better method of induction, this study shows that Foleys induction has reduced side effects and is also cost effective, making it a superior method for cervical ripening.
\end{abstract}

Keywords: Cervical ripening, Foleys catheter, Induction, ProstaglandinE2 gel

\section{INTRODUCTION}

Induction of labour is a common obstetric intervention, occurring in approximately $25 \%$ of term pregnancies in developing countries. The increased ceserean delivery risk associated with induction is strongly influenced by the induction attempt duration, especially with an unfavourable cervix. ${ }^{1}$

The condition of the cervix described as cervical "ripeness" or "favourability" is important to successful labour induction. There are pharmacological and mechanical methods that can enhance cervical favourability, also termed preinduction cervical ripening. ${ }^{2}$
Pharmocological and mechanical methods commonly used are prostaglandin preparations (PGE1 and PGE2) and various intracervical catheters (single or double balloon), respectively. Mechanical methods not only dilate the cervix, but also increase prostaglandin and oxytocin release by causing localised inflammation, while prostaglandins act to promote both cervical ripening and uterine activity.

The success of labor induction varies based on the state of cervix before ripening, which is measured by the Modified Bishop's score. If the score is low or unfavourable, then modes of ripening of the cervix are used to increase the chances of a vaginal delivery. ${ }^{3}$ 
Table 1: Modified bishops score.

\begin{tabular}{|lllll|}
\hline \multicolumn{5}{l}{ SCORE } \\
Dilation $(\mathrm{cm})$ & 0 & 1 & 2 & 3 \\
\hline Length $(\mathrm{cm})$ & $<1$ & $1-2$ & $2-4$ & $>4$ \\
\hline Station $(\mathrm{cm})$ & $>4$ & $2-4$ & $1-2$ & $<1$ \\
\hline Consistency & -3 & -2 & $-1 / 10$ & $+1 /+2$ \\
\hline Position & Firm & Medium & Soft \\
\hline Anterior & Posterior & $\begin{array}{l}\text { Mid- } \\
\text { position, } \\
\text { Anterior }\end{array}$ \\
& & & \\
\hline
\end{tabular}

Aim of the study was to determine the safety and efficacy of Foleys catheter compared to dinoprostone gel for preinduction cervical ripening in women with an unfavourable cervix.

\section{The Primary outcome measure}

Vaginal delivery within 24 hours.

\section{Secondary outcome measures}

\section{To compare}

1. Improvement in Bishops score in both groups.

2. Induction to onset of active labour and induction to delivery interval in both the groups.

3. Mode of delivery in both groups.

4. Occurrence of maternal complications and fetal outcome in both groups.

5. Cost effectiveness of both groups.

\section{METHODS}

The present study was carried out at Raja Sir Ramasamy Mudaliar Hospital, Chennai during the period August 2012 to July 2013. All pregnant women who satisfy the inclusion and exclusion criteria were included in the study after getting an informed consent from both the patient and their husband.

\section{Inclusion criteria}

1. Singleton gestation

2. Gestational age more than 34 weeks

3. Cephalic presentation

4. Medical indication for labor induction.

5. Bishop score of $\leq 5$

6. Reactive fetal heart rate (FHR) on admission

7. Intact membranes

\section{Exclusion criteria}

1. Any condition precluding vaginal delivery

2. Any contraindication to receiving prostaglandins, such as history of Bronchial asthma, cardiovascular disease or glaucoma.
3. Previous cesarean section or any other uterine incision

4. Placenta praevia

5. Active infection of genital tract

6. Abnormal fetal heart rate (FHR).

7. Latex allergy.

After being included in the study the patients were randomly allocated to either prostaglandinE2 gel group or the Foleys group.

The time of application of intracervical prostaglandin or insertion of foleys catheter is taken as zero hour. Patient's name, age, parity and gestational age were noted. The indication for induction was noted. A routine obstetric scan was done. General, abdominal and vaginal examination was done.

The method most commonly used to identify cervical ripening is the modified Bishop score which is a quantitative measure of consistency, dilation of the cervix, station, position of the presenting part. Preinduction modified Bishops score distribution should be similar both between groups. All patients were monitored with the partogram.

In the women recruited in the PGE2 group, Prostaglandin gel (PGE2 gel) $0.5 \mathrm{mg}$ available in a preloaded syringe was placed in the endocervical canal under strict aseptic precautions. A repeat dose of prostaglandin gel (PGE2 gel) was given to patients with no improvement in bishops score after 6 hours. In patients with improvement in bishops score, labour was augmented with oxytocin after 6 to 12 hours since the time of induction. Fetal heart rate monitoring was done before then after each PGE2 insertion for a minimum of 20 minutes.

In the second group, a Foleys catheter was inserted into the cervical canal, and is filled with $30 \mathrm{ml}$ of saline above the level of the internal os and pulled snugly back against the os. The catheter was strapped to the inner aspect of one thigh on slight tension for twelve hours. The catheter was then removed after 12 hours if spontaneous expulsion had not occurred. EFM (Electronic fetal heart monitoring) was conducted before and after induction for a minimum of 20 minutes. Artificial rupture of the membranes and oxytocin infusion was then started if there was improvement in the bishop's score.

The change in bishops score, induction to delivery interval with associated maternal complications, need for oxytocin induction, mode of delivery, incidence of caesarean sections with the indications, vaginal delivery within 24 hours between both groups were compared.

The weight and 5 minute APGAR of all newborn delivered were tabulated.

All parameters were tabulated and statistical analysis done. $\mathrm{P}$ value $<0.05$ is taken as significant. 
RESULTS

Table 2: Age group distribution.

\begin{tabular}{|lllll|}
\hline $\begin{array}{l}\text { Age } \\
\text { group in } \\
\text { years }\end{array}$ & Group & & \\
\hline \multirow{2}{*}{$18-20$} & Foleys & PGE2 & Total \\
& $\begin{array}{l}\text { Count } \\
\text { \% within } \\
\text { Group }\end{array}$ & 35 & 45 & 80 \\
\hline \multirow{2}{*}{$21-25$} & Count & 53 & $45.0 \%$ & $40.0 \%$ \\
\cline { 2 - 5 } & $\begin{array}{l}\text { \% within } \\
\text { Group }\end{array}$ & $53.0 \%$ & $42.0 \%$ & $47.5 \%$ \\
\hline \multirow{2}{*}{$26-30$} & Count & 9 & 10 & 19 \\
\cline { 2 - 5 } & $\begin{array}{l}\text { \% within } \\
\text { Group }\end{array}$ & $9.0 \%$ & $10.0 \%$ & $9.5 \%$ \\
\hline \multirow{2}{*}{ Above 30 } & Count & 3 & 3 & 6 \\
\cline { 2 - 5 } & $\begin{array}{l}\text { \% within } \\
\text { Group }\end{array}$ & $3.0 \%$ & $3.0 \%$ & $3.0 \%$ \\
\hline Mean & & $22.24 \mathrm{yrs}$ & $22.22 \mathrm{yrs}$ \\
\hline
\end{tabular}

$\mathrm{P}=0.462$

The age group distribution between the two groups was found to be comparable. There was no statistical difference between the age distribution of both the groups
$(\mathrm{P}=0.462)$. Majority of patients were in the age group 21$25 y r s$ in Foleys group and 18-20yrs in the PGE2 group. The mean age in the Foleys group was 22.24yrs and PGE2 group was 22.22yrs.

The parity distribution between the two groups were found to be comparable. There was no statistical difference between the two groups $(\mathrm{P}=0.508)$. There were 74 nulliparas in the foleys group and 78 in the PGE2 group.

Table 3: Parity distribution.

\begin{tabular}{|c|c|c|c|c|c|}
\hline & & & \multicolumn{2}{|l|}{ Group } & \multirow[t]{2}{*}{ Total } \\
\hline & & & Foleys & PGE 2 & \\
\hline \multirow[t]{4}{*}{ Parity } & Primi & Number & 74 & 78 & 152 \\
\hline & & $\begin{array}{l}\% \text { within } \\
\text { Parity }\end{array}$ & $48.7 \%$ & $51.3 \%$ & $\begin{array}{l}100.0 \\
\%\end{array}$ \\
\hline & Multi & Number & 26 & 22 & 48 \\
\hline & & $\begin{array}{l}\% \text { within } \\
\text { Parity }\end{array}$ & $54.2 \%$ & $45.8 \%$ & $\begin{array}{l}100.0 \\
\%\end{array}$ \\
\hline \multirow[t]{2}{*}{ Total } & & Number & 100 & 100 & 200 \\
\hline & & $\begin{array}{l}\% \text { within } \\
\text { Parity }\end{array}$ & $50.0 \%$ & $50.0 \%$ & $\begin{array}{l}100.0 \\
\%\end{array}$ \\
\hline
\end{tabular}

$\mathrm{P}=0.508$

Table 4: Gestational age distribution.

\begin{tabular}{|c|c|c|c|c|c|}
\hline \multirow{3}{*}{ Gestational Age in days } & \multirow[b]{3}{*}{ Below 260} & \multirow[b]{3}{*}{ Number } & \multicolumn{2}{|l|}{ Group } & \multirow[t]{2}{*}{ Total } \\
\hline & & & Foleys & PGE 2 & \\
\hline & & & 14 & 18 & 32 \\
\hline & & $\%$ within Gestational Age in days & $43.8 \%$ & $56.3 \%$ & $100.0 \%$ \\
\hline & $260-280$ & Number & 49 & 49 & 98 \\
\hline & & $\%$ within Gestational Age in days & $50.0 \%$ & $50.0 \%$ & $100.0 \%$ \\
\hline & Above 280 & Number & 37 & 33 & 70 \\
\hline & & $\%$ within Gestational Age in days & $52.9 \%$ & $47.1 \%$ & $100.0 \%$ \\
\hline
\end{tabular}

$\mathrm{P}=0.695$

Table 5: Indication for induction distribution.

\begin{tabular}{|c|c|c|c|c|c|}
\hline & & & \multicolumn{2}{|l|}{ Group } & \multirow{2}{*}{ Total } \\
\hline & & & Foleys & PGE 2 & \\
\hline \multirow[t]{14}{*}{ INDI } & Post dated & Number & 36 & 32 & 68 \\
\hline & & $\%$ within INDI & $52.9 \%$ & $47.1 \%$ & $100.0 \%$ \\
\hline & $\mathrm{PIH}$ & Count & 18 & 28 & 46 \\
\hline & & $\%$ within INDI & $39.1 \%$ & $60.9 \%$ & $100.0 \%$ \\
\hline & & Count & 28 & 22 & 50 \\
\hline & Oligohydrannios & $\%$ within INDI & $56.0 \%$ & $44.0 \%$ & $100.0 \%$ \\
\hline & GDM & Count & 9 & 11 & 20 \\
\hline & & $\%$ within INDI & $45.0 \%$ & $55.0 \%$ & $100.0 \%$ \\
\hline & IUGR & Count & 6 & 5 & 11 \\
\hline & & $\%$ within INDI & $54.5 \%$ & $45.5 \%$ & $100.0 \%$ \\
\hline & Anomalous & Count & 1 & 1 & 2 \\
\hline & & $\%$ within INDI & $50.0 \%$ & $50.0 \%$ & $100.0 \%$ \\
\hline & IUFD & Count & 2 & 1 & 3 \\
\hline & & $\%$ within INDI & $66.7 \%$ & $33.3 \%$ & $100.0 \%$ \\
\hline
\end{tabular}

$\mathrm{P}=0.710$ (INDI- Indication, PIH - Pregnancy induced hypertension, GDM- Gestational diabetes mellitus, IUGR - Intra Uterine Growth restriction, IUFD- Intra Uterine Fetal Death). 
The mean gestational age in the foleys group was 270.60 days and in the PGE2 group was 269.64 days. There is no statistical difference in the gestational age of both the groups $(\mathrm{P}=0.521)$.

The commonest indication for induction in both the groups was postdated pregnancy (36) in the Foleys group and (32) in the PGE2 group. There was no significant difference between the two groups $(\mathrm{P}=0.710)$. The second common indication was oligohydramnios (28) in the Foleys group and preeclampsia (28) in the PgE2 group. There were 2 cases of intrauterine fetal death in the Foleys group and one in the PgE2 group.

The bishops score at the start of induction, i.e. bishops score at zero hours in the foleys group was a mean of 2.09 in nulliparas and 3.27 in the para-1 patients which was statistically significant $(\mathrm{P}=<0.001)$. However the change in bishops score after 12 hours of induction was a mean of 5.55 in the nulliparas group and 6.70 in the para1 group which was not statistically significant $(\mathrm{P}=0.016)$.

The bishops score at induction in the PGE2 group was 1.95 in nulliparas and 2.55 in the para- 1 patients, which was not statistically significant $\mathrm{P}=0.019$. The change in bishops score was a mean of 4.65 in the nullipara and 6.06 in the para-1 patients respectively which was statistically very significant $\mathrm{P}=0.004$. Thus, $\mathrm{PGE} 2$ gel in my study increases the bishops score very significantly in the para-1 patients compared to the Nullipara patients.

The mean bishop's score in the Foleys group was 2.40 and in the PGE2 group was 2.08 and it was not statistically significant $(\mathrm{P}=0.071)$. The mean change in bishops score in the Foleys group was 5.80 and in the PGE2 group was 4.92 which was statistically very significant $\mathrm{P}=0.002$. Hence Foleys catheter was found to increase the bishops score better than PGE2 gel. In the Foleys group $56.8 \%$ of nulliparas and $84.6 \%$ of para-1 women delivered by spontaneous vaginal delivery, whereas in the PGE2 group $69.2 \%$ of the nulliparas and
$50 \%$ of the para- 1 patients delivered vaginally. This was not found to be statistically significant.

Table 6: Bishops score at induction and change in bishops score (Distribution in both groups).

\begin{tabular}{|c|c|c|c|c|}
\hline $\begin{array}{l}\text { Bishops } \\
\text { score }\end{array}$ & Group & No. & Mean & $\begin{array}{l}P \\
\text { value }\end{array}$ \\
\hline \multirow{2}{*}{$\begin{array}{l}\mathrm{B}_{\mathrm{O}} \text { (bishops } \\
\text { at zero hour) }\end{array}$} & Foleys & 100 & 2.40 & \multirow{2}{*}{0.071} \\
\hline & PGE2 & 100 & 2.08 & \\
\hline \multirow{2}{*}{$\begin{array}{l}\text { Change in } \\
\text { bishops } \\
\operatorname{score}\left(B_{Z}\right)\end{array}$} & Foleys & 93 & 5.80 & \multirow[b]{2}{*}{0.002} \\
\hline & $\begin{array}{l}\text { PGE2 (with } \\
\text { one gel) }\end{array}$ & 89 & 4.92 & \\
\hline
\end{tabular}

$33.8 \%$ of the nulliparas in the Foleys group delivered by caesarean section and $11.5 \%$ of para-1 patients delivered by caesarean section. In the PGE2 group, $25.6 \%$ of the nulliparas delivered by caesarean section and 40.9 of the para-1 patients delivered by caesarean section. The difference was found to be statistically significant for the para-1 group $(\mathrm{P}=0.005)$.

$9.5 \%$ of the nulliparas and $3.8 \%$ of para- 1 patients in the Foleys group, $5.1 \%$ of nulliparas and $9.1 \%$ of the para-1 patients in the PGE2 group delivered by outlet forceps.

However the mean of the mode of delivery between both the groups was not statistically significant $(\mathrm{P}=0.856)$.

The comparison of the indications for caesarean section in both the groups showed a statistical significance $\mathrm{P}=0.050$

In both the Foleys and the PGE2 group, with respect to nulliparas, failed induction was the commonest indication-56.3\% (18 patients) in the Foleys group and $45.8 \%$ (11 patients) in the PGE2 group. The second common indication for LSCS was fetal distress in both the groups with respect to nulliparas-9.4\% (3 patients) in the Foleys and $33.3 \%$ ( 8 patients) in the PGE2 group respectively which is statistically significant.

Table 7: Mode of delivery and parity group distribution.

\begin{tabular}{|c|c|c|c|c|c|c|}
\hline & & & & Parity & & Tatol \\
\hline & & & & Primi & Multi & lotal \\
\hline Foleys & Mode of delivery & $\mathrm{LN}$ & Number & 42 & 22 & 64 \\
\hline & & & $\%$ within Parity & $56.8 \%$ & $84.6 \%$ & $64.0 \%$ \\
\hline & & LSCS & Number & 25 & 3 & 28 \\
\hline & & & $\%$ within Parity & $33.8 \%$ & $11.5 \%$ & $28.0 \%$ \\
\hline & & $\mathrm{OF}$ & Number & 7 & 1 & 8 \\
\hline & & & $\%$ within Parity & $9.5 \%$ & $3.8 \%$ & $8.0 \%$ \\
\hline PGE 2 & Mode of delivery & LN & Number & 54 & 11 & 65 \\
\hline & & & $\%$ within Parity & $69.2 \%$ & $50.0 \%$ & $65.0 \%$ \\
\hline & & LSCS & Number & 20 & 9 & 29 \\
\hline & & & $\%$ within Parity & $25.6 \%$ & $40.9 \%$ & $29.0 \%$ \\
\hline & & $\mathrm{OF}$ & Number & 4 & 2 & 6 \\
\hline & & & $\%$ within Parity & $5.1 \%$ & $9.1 \%$ & $6.0 \%$ \\
\hline
\end{tabular}

(LN - Labour natural, LSCS- Lower segment caesarean section, OF - outlet forceps) 
Table 8: LSCS indication group distribution.

\begin{tabular}{|c|c|c|c|c|c|c|}
\hline \multirow{2}{*}{ Group } & & & & \multicolumn{2}{|l|}{ Parity } & \multirow{2}{*}{ Total } \\
\hline & & & & \multicolumn{2}{|r|}{ Multi } & \\
\hline Foleys & LSCS Indication & FI & Number & 18 & 1 & 19 \\
\hline & & & $\%$ within LSCS & $94.7 \%$ & $5.3 \%$ & $100.0 \%$ \\
\hline & & & $\%$ within Parity & $56.3 \%$ & $25.0 \%$ & $52.8 \%$ \\
\hline & & FD & Number & 3 & 2 & 5 \\
\hline & & & $\%$ within LSCS & $60.0 \%$ & $40.0 \%$ & $100.0 \%$ \\
\hline & & & $\%$ within Parity & $9.4 \%$ & $50.0 \%$ & $13.9 \%$ \\
\hline & & $\mathrm{F}$ to $\mathrm{P}$ & Number & 2 & 0 & 2 \\
\hline & & & $\%$ within LSCS & $100.0 \%$ & $.0 \%$ & $100.0 \%$ \\
\hline & & & $\%$ within Parity & $6.3 \%$ & $.0 \%$ & $5.6 \%$ \\
\hline & & CPD & Number & 2 & 0 & 2 \\
\hline & & & $\%$ within LSCS & $100.0 \%$ & $.0 \%$ & $100.0 \%$ \\
\hline & & & $\%$ within Parity & $6.3 \%$ & $.0 \%$ & $5.6 \%$ \\
\hline Pge 2 & LSCS Indication & FI & Number & 11 & 2 & 13 \\
\hline & & & $\%$ within LSCS & $84.6 \%$ & $15.4 \%$ & $100.0 \%$ \\
\hline & & & $\%$ within Parity & $45.8 \%$ & $18.2 \%$ & $37.1 \%$ \\
\hline & & FD & Number & 8 & 8 & 16 \\
\hline & & & $\%$ within LSCS & $50.0 \%$ & $50.0 \%$ & $100.0 \%$ \\
\hline & & & $\%$ within Parity & $33.3 \%$ & $72.7 \%$ & $45.7 \%$ \\
\hline & & $\mathrm{F}$ to $\mathrm{P}$ & Number & 1 & 0 & 1 \\
\hline & & & $\%$ within LSCS & $100.0 \%$ & $.0 \%$ & $100.0 \%$ \\
\hline & & & $\%$ within Parity & $4.2 \%$ & $.0 \%$ & $2.9 \%$ \\
\hline & & CPD & Number & 2 & 0 & 2 \\
\hline & & & $\%$ within LSCS & $100.0 \%$ & $.0 \%$ & $100.0 \%$ \\
\hline & & & $\%$ within Parity & $8.3 \%$ & $.0 \%$ & $5.7 \%$ \\
\hline
\end{tabular}

(FI - Failed induction, FD- Fetal distress, F to P- Failure to progress, CPD - Cephalopelvic disproportion)

Table 9: Vaginal delivery in 24 hours group distribution.

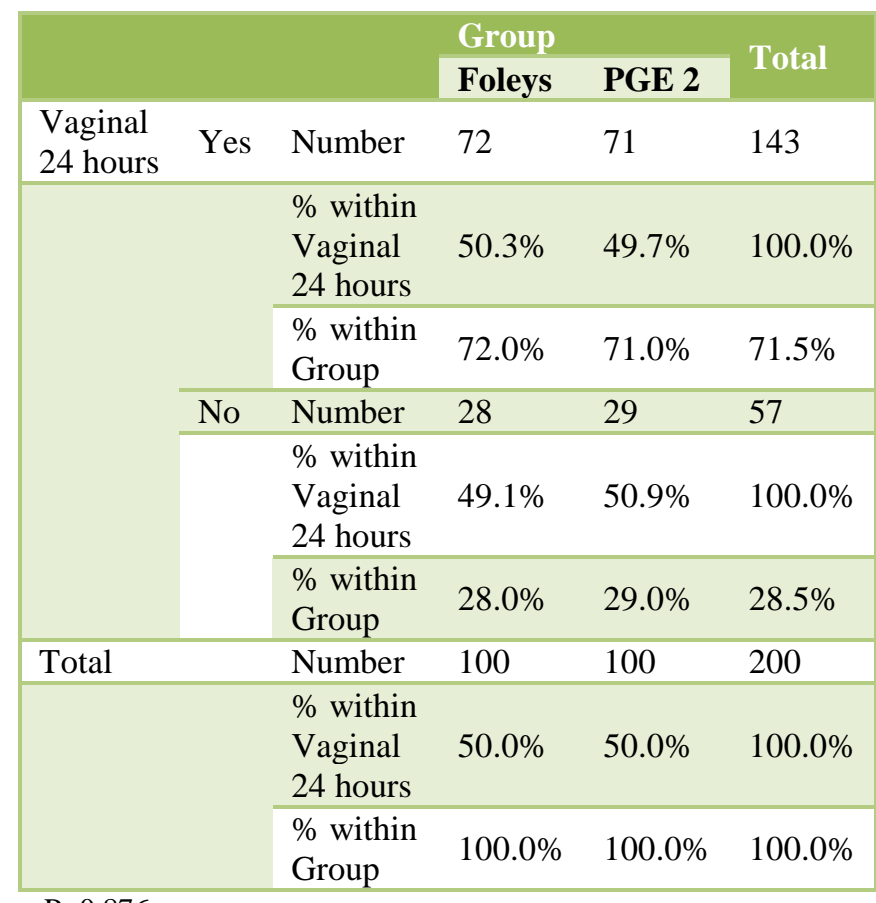

$\mathrm{P}=0.876$
In para-1 patients in the Foleys group of 3 patients who delivered by caesarean section, 2 patients indication for LSCS was fetal distress (50\%). In the PGE2 group, para1 patients 8 underwent LSCS for fetal distress $(72.7 \%)$ which is statistically significant.

Out of 100 patients in each group, the number of patients delivering vaginally within $24 \mathrm{hrs}$ was comparable between the two groups, 72 patients in the Foleys group and 71 in the pge 2 group with no statistical difference $(\mathrm{P}=0.876)$.

The number of patients in the PGE2 group developing nonreassuring fetal heart rate during induction and subsequently ending up in caesarean section was 9 compared to none in the Foleys group. This was statistically very significant $(\mathrm{P}=0.002)$.

7 patients in the PGE2 group developed hyper stimulation to induction but there were no adverse affects in the Foleys group which was statistically very significant $(\mathrm{P}=0.007)$. 
Table 10: Non-reassuring FHR in the induction group distribution.

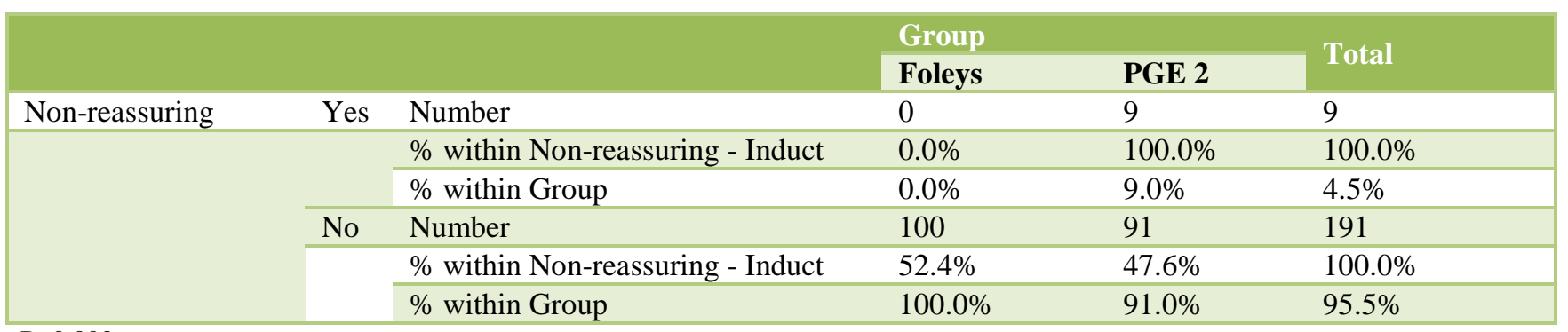

Table 11: Maternal complication group distribution.

\begin{tabular}{|c|c|c|c|c|c|}
\hline & & & Group & & Tetol \\
\hline & & & Foleys & PGE 2 & 10tal \\
\hline $\mathrm{MC}$ & Yes & Number & 0 & 7 & 7 \\
\hline & & $\begin{array}{l}\% \text { within } \\
\text { MC }\end{array}$ & $0.0 \%$ & $100.0 \%$ & $100.0 \%$ \\
\hline & & $\begin{array}{l}\% \text { within } \\
\text { Group }\end{array}$ & $0.0 \%$ & $7.0 \%$ & $3.5 \%$ \\
\hline & No & Number & 100 & 93 & 193 \\
\hline & & $\begin{array}{l}\% \text { within } \\
\text { MC }\end{array}$ & $51.8 \%$ & $48.2 \%$ & $100.0 \%$ \\
\hline & & $\begin{array}{l}\% \text { within } \\
\text { Group }\end{array}$ & $100.0 \%$ & $93.0 \%$ & $96.5 \%$ \\
\hline
\end{tabular}

$\mathrm{P}=0.007$, (MC- maternal complications)

Table 12: Second gel group distribution.

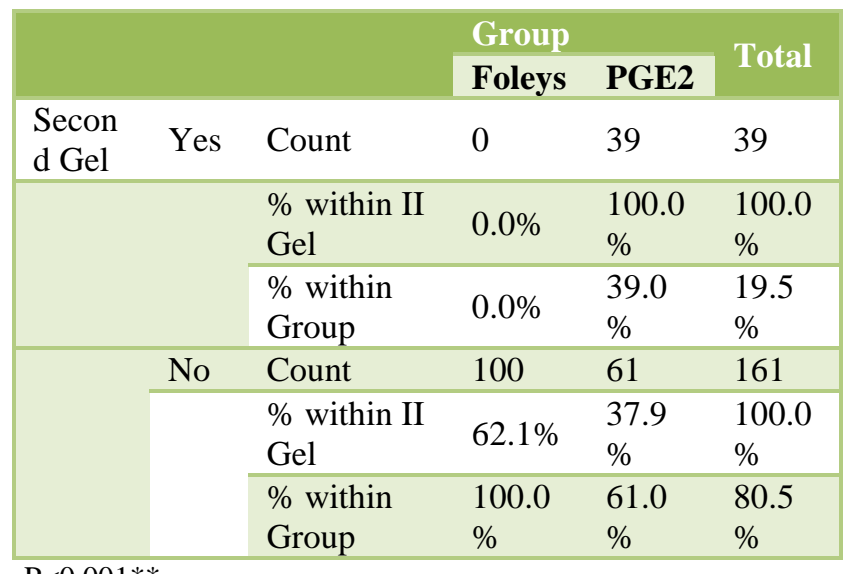

$\mathrm{P}<0.001 * *$

$39 \%$ of patients in the PGE2 group needed regel as bishops score was not favorable after induction with one PGE2 gel. This was statistically very significant $\mathrm{P}<0.001 * *$.

Table 13: Birth weight distribution.

\begin{tabular}{|lllll|}
\hline & Group & N & Mean & P Value \\
\cline { 1 - 3 } $\begin{array}{l}\text { Birth } \\
\text { weight }\end{array}$ & Foleys & 100 & 2.8442 & \multirow{2}{*}{0.429} \\
\cline { 1 - 3 } & PGE 2 & 100 & 2.8886 & \\
\hline
\end{tabular}

The average birth weight of the newborn in the Foleys group was 2.8442 kilograms and in the pge2 group was 2.8886 kilograms which was not statistically significant $(\mathrm{P}=0.429)$.

Table 14: Neonatal outcome.

\begin{tabular}{|lllll|} 
& Group & N & Mean & P value \\
\cline { 1 - 4 } APGAR & Foleys & 96 & 8.07 & \multirow{2}{*}{0.099} \\
\hline & PGE2 & 97 & 8.27 & \\
\hline $\mathrm{P}=0.099$ & & & & \\
\hline
\end{tabular}

$\mathrm{P}=0.099$

The mean APGAR in the Foleys group was 8.07 and in the PgE2 group was 8.27 with no statistical significance between the groups $(\mathrm{P}=0.099)$.

\section{DISCUSSION}

In our study, the age group distribution was even between both the groups. The mean age group in the Foleys group was 21-25 yrs and 18-20 yrs in the PGE2 group. This is similar to other studies where similar age group patients were included in both the groups.

In our study, the parity distributions between the two groups were found to be comparable. Study done by Jackson et al included 50 patients, both nulliparous and para-1 patients similar to the present study whereas some studies were done exclusively on nulliparous women such as a study by Ekman et al included only 20 nulliparous women and study by Bernstein et al included 100 nulliparous women. ${ }^{4-6}$

The mean gestational age in days in the Foleys group is 270.60days and in the PGE2 group is 269.64 days. The maximum numbers of patients were in the 260-280 days group in both the groups. Studies done by Jackson et al, Ekman et al all included term pregnant women like the present study. ${ }^{4,5}$

In our study women with bishop score $\leq 5$ were included. Studies done by Herabutya et al and Bernstein et al included women with bishops score $\leq 4$. ${ }^{7,6}$ However in a study by Egarter et al, Sciscione et al and Ashrafunnessa et al included women with bishops score $\leq 5$. $^{8-10}$

In our study, Foleys catheter was found to increase the bishops score better then PGE2 gel. In a study by 
Niromanesh et al, ninety women with a Bishop score of $\leq 5$ were randomized to receive an intracervical Foleys catheter or prostaglandin E2 gel. ${ }^{11}$ No difference was seen in the mean Bishop Scores between the 2 groups. In another similar study by Sciscione et al, 77 mothers were included into Foley group and 72 in PGE2 gel group. ${ }^{9}$ Bishop score after ripening $(6.5$ and 5.1, $\mathrm{P}<0.001)$ and change in Bishop score (3.5 and 2.7, $\mathrm{P}=0.015)$ was higher in Foleys group.

In our study, a significant difference in the induction delivery interval between the two groups was seen. The mean duration in Foleys group was 16.48 hours and PGE2 group was $14.66 \mathrm{hrs}$. In a study by Antonella Cromi et al, $74 \%$ of the Foleys group and $72 \%$ of the PGE2 group delivered vaginally within 24 hours with the mean induction delivery interval being $16.32 \mathrm{hrs}$ in the foleys group and $15.27 \mathrm{hrs}$ in the PGE2 group which was not statistically significant. ${ }^{12}$ Zvi Vaknin et al compared the safety and efficacy of Foleys catheter and intravaginal dinoprostone for cervical ripening. The time taken for cervical ripening and the time for vaginal delivery was better in the foleys group. ${ }^{13}$ There was no much difference between both groups in rates of cesarean sections. Prostaglandins had an increased risk of uterine hyperactivity $(\mathrm{P}=0.001)$. Foleys group had more need of oxytocin in labour $(\mathrm{P}=0.0002)$.

In the study done by Sciscione et al, the Foleys catheter caused a high postinduction Bishop score, a higher change in Bishop score, less time for induction, but were similar in terms of mode of delivery. ${ }^{9}$ In Foleys and PGE2 group, with respect to nulliparas, failed induction was the commonest indication for caesarean section$56.3 \%$ (18 patients) in Foleys group and 45.8\% (11 patients) in PGE2 group. $39 \%$ of patients in the PGE2 group needed regel as bishops' score was not favourable after induction with one PGE2 gel. This was statistically very significant $(\mathrm{P}<0.001)$.

In a similar study done by Jozwiack et al, 82 patients were randomly assigned for cervical ripening with Foleys catheter and PGE2 gel. Four cases of failed induction of labour in Foleys group were seen and 0 in the PGE2 group $(\mathrm{P}<0.05){ }^{14}$ The second common indication for LSCS was fetal distress in both the groups with respect to nulliparas. 9.4\% (3 patients) in the Foleys and 33.3\% (8 patients) in the PGE2 group respectively which was statistically significant. In the para-1 patients in the Foleys group, out of 3 patients who delivered by caesarean section, 2 patients indication for LSCS was fetal distress $(50 \%)$. In the PGE2 group, 8 para- 1 patients underwent LSCS for fetal distress $(72.7 \%)$ which was again statistically significant. The number of patients in the PGE2 group developing non reassuring fetal heart rate during induction and subsequently ending up in caesarean section was 9 compared to none in the Foleys group. This was statistically very significant. 7 patients in the PGE2 group developed hyperstimulation to induction but there were no adverse affects in the Foleys group which was statistically very significant. Thus PGE2 was associated with a significant occurrence of non reassuring fetal heart variabilities and maternal complications compared to the foleys group.

In the study done by Sciscione et al, no significant difference in both groups for mode of delivery, birth weight, and occurence of uterine hyperactivity, patient discomfort, use of epidural analgesia, use of oxytocin, or abnormal fetal heart rate was seen. ${ }^{10}$

In the study done by Jozwiack et al 3 cases hyperactivity occurred which required cesarean delivery in the PGE2 group and none in the Foleys group. ${ }^{14}$ The outcome of pregnancy was otherwise similar in both groups.

The cost in the Foleys group was 40 rupees per catheter per patient and it was hundred rupees per patient per gel in the pge 2 group thus making the Foleys group cost effective.

\section{CONCLUSION}

In the present study comparing prostaglandin E2 intracervical gel and foleys catheter as preinductional cervical ripening agents, the primary outcome, vaginal delivery within 24 hours was similar between the two groups. The study demonstrates that Foleys catheter yields similar caesarean section rates compared to prostaglandinE2 gel, making both methods equally effective. Foleys catheter was found to increase the bishops score better than prostaglandin E2 gel but the induction to delivery interval was significantly shorter in the PGE2 group. The occurrence of fetal heart abnormalities was significantly more in PGE2 group. The 5 minute APGAR and birth weight was similar between two groups. Thus Foleys catheter can be useful as a ripening agent in low-resource countries, due to low cost, easy storage, and decreased need of fetal surveillance during the ripening phase of induction. This makes Foleys catheter a superior method, with the potential for even outpatient cervical ripening.

\section{Funding: No funding sources}

Conflict of interest: None declared

Ethical approval: The study was approved by the Institutional Ethics Committee

\section{REFERENCES}

1. Spong CY, Berghella V, Wenstrom KD, Mercer BM, Saade GR. Preventing the first cesarean delivery: summary of a joint Eunice Kennedy Shriver national institute of child health and human development, society for maternal-fetal medicine, and American college of obstetricians and gynecologists workshop. Obstetrics and gynecology. 2012 Nov;120(5):1181.

2. Gary CF, Kenneth LJ, Steven BL, Catherine SY, Jodi DS, Barbara HL, Williams obstetrics $24^{\text {th }}$ Edition, Chapter 26; 2014:525. 
3. Arias' Practical guide to High-Risk Pregnancy and Delivery: A South Asian Perspective, 4/e, Bhide, Arulkumaran, Damania, Daftary. Chapter 9; 2015:147.

4. Jackson GM, Sharp HT, Varner MW. Cervical ripening before induction of labor: A randomized trial of prostaglandin E2gel versus low-dose oxytocin. American journal of obstetrics and gynecology. 1994 Oct 1;171(4):1092-6.

5. Ekman G, Ulman U, Winger up L. Intracervical prostaglandin E2 gel vs intravenous infusion of oxytocin for induction at term. Arch Gynaec. 1983;234:61-65.

6. Bernstein P, Leyland N, Gurland P, Gare D. Cervical ripening and labour induction with prostaglandin E2 gel: a placebo controlled study. Am J of Obstet Gynaecol. 1987;156:336-340.

7. Herabutya Y, Prasertsawat P. Induction of labour using intracervical prostaglandinE2 gel:the outcome. J Medical Association Thai. 1991;74:491-7.

8. Egarter C, Grunberger W, Huslein P. Prostaglandin Gel For Ripening The Cervix At The End Of Pregnancy. Z Geburtshilfe Perinatol. 1986;190:83-6.

9. Sciscione AC, Nguyen L, Manley J, Pollock M, Maas B, Colmorgen G. A randomized comparison of transcervical Foley catheter to intravaginal misoprostol for preinduction cervical ripening. Obster Gynecol. 2001;97(4):603-7.

10. Khatun SS, Chowdhury SA, Begum SR, Rashid M, Khatun MS. Induction of labor by intracervical prostaglandin gel and oxytocin infusion in primigravid women with unfavorable cervix. Bangladesh Medical Research Council bulletin. 1997 Dec;23(3):66-71.

11. Niromanesh S, Mosavi-Jarrahi A, Samkhaniani F. Intracervical Foley catheter balloon vs. prostaglandin in preinduction cervical ripening. International Journal of Gynecology and Obstetrics. 2003;81:23-7.

12. Cromi A, Ghezzi F, Agosti M, Serati M, Uccella S, Arlant V, et al. Is transcervical Foley catheter actually slower than prostaglandins in ripening the cervix? A randomized study. American Journal of obstetrics and gynecology. 2011;204(4):338-e1.

13. Vaknin Z, Kurzweil Y, Sherman D. Foley catheter balloon vs locally applied prostaglandins for cervical ripening and labor induction: a systematic review and metaanalysis. Am J Obstet Gynecol. 2010;203(5):418-29.

14. Jozwiak M, Benthem M, Rengerink KO, Dijksterhuis M, de Graaf I, van Pampus M, et al. 62: Randomized clinical trial for the comparison of Foley catheter and prostaglandin inserts in induction of labor at term (trial registration NTR 1646). Am J Obstet Gynecol. 2012;206(1):S40.

Cite this article as: Mumtaj M, Harilakshmi M. A randomised controlled trial of preinduction cervical ripening-dinoprostone versus foleys catheter. Int J Reprod Contracept Obstet Gynecol 2017;6:2387-94. 